\title{
Toxic Alcohol Ingestion: A Case Report and Review of Management Pathways
}

Paavani Atluri ${ }^{1}$, Deepa Vasireddy ${ }^{2}$, Srikrishna V. Malayala ${ }^{3}$

1. Internal Medicine, Bay Area Hospital, Coos Bay, USA 2. Pediatrics, Pediatric Group of Acadiana, Lafayette, USA 3. Internal Medicine, Temple University Hospital, Philadelphia, USA

Corresponding author: Paavani Atluri, paavani.atluri@gmail.com

\begin{abstract}
Toxic alcohol ingestion can be fatal or produce irreversible tissue damage and hence timely recognition and treatment are very important. The physician has to often rely on clinical features and different lab values in order to derive the possible causative agent consumed. Gas chromatography is the definitive diagnostic test to detect the toxic alcohol but is unfortunately not available to run in house in most hospital laboratories in the acute clinical setting. We present a 41-year-old gentleman who was brought to the ED for further evaluation of vomiting and upper abdominal pain. Our clinical impression was that the patient had possible mixed toxic alcohol ingestion. General principles and treatment of alcohol intoxication include gastric lavage or use of activated charcoal. Administration of ethanol or fomepizole to delay or prevent generation of toxic metabolites needs to be initiated while sufficient alcohol remains and metabolized and measurement of blood alcohol concentrations and/or serum osmolality can be helpful. Dialysis is helpful in removing unmetabolized alcohol and possibly toxic metabolites and delivering base to patients to ameliorate metabolic acidosis.
\end{abstract}

Review began $01 / 26 / 2021$ Review ended 01/27/2021 Published 02/03/2021

\section{๑) Copyright 2021}

Atluri et al. This is an open access article distributed under the terms of the Creative Commons Attribution License CC-BY 4.0., which permits unrestricted use, distribution, and reproduction in any medium, provided the original author and source are credited.
Categories: Emergency Medicine, Internal Medicine, Public Health

Keywords: toxic alcohol, methanol, ethylene glycol, diethylene glycol, propylene glycol, isopropanol, fomepizole

\section{Introduction}

Methanol, ethylene glycol, diethylene glycol, propylene glycol, and isopropanol are the common alcohols whose consumption can lead to toxic ingestions [1]. Toxic ingestions can lead to neurological impairment of the patient and can make eliciting an accurate history of what was consumed challenging for the treating physician [2]. The physician has to often rely on clinical features and different lab values in order to derive the possible causative agent consumed. Gas chromatography is the definitive diagnostic test to detect the toxic alcohol but is unfortunately not available to run in house in most hospital laboratories in the acute clinical setting [3]. According to the 2019 National Survey on Drug Use and Health (NSDUH), $25.8 \%$ of people aged 18 or older reported that they engaged in binge drinking in the past month while $6.3 \%$ reported that they engaged in heavy alcohol use in the past month [4]. An estimated 95,000 people with a male predominance died every year from alcohol-related causes [4-5]. Alcohol is the third leading preventable cause of death in the United States [4].

\section{Case Presentation}

We present a 41-year-old gentleman with a known history of alcoholism who was brought to the ED by emergency medical services for further evaluation of vomiting and upper abdominal pain. The patient usually drinks two to three beers at least two to three times per week and as he ran out of alcohol, he admitted to drinking two shots of industrial alcohol. Interpreter services were used as the patient was Spanish speaking. The patient was alert, awake and oriented in time, place and person. He was very tremulous on admission. He denied having headache, vision changes, chest pain, chest pressure, shortness of breath, abdominal pain, recent changes in bowel or bladder habits. He admitted to mixing rubbing alcohol with soda and the amount of ingestion of industrial alcohol remained unclear. Blood alcohol was checked on admission and was noted to be negative at less than $10 \mathrm{mg} / \mathrm{dL}$. He did have significant anion gap metabolic acidosis with compensated severe metabolic alkalosis and respiratory alkalosis. Usually anion gap is not seen in patients with isopropyl alcohol ingestion and hence upon further investigation the patient is not sure as to what he consumed.

He was noted to have lactic acidosis of $4.4 \mathrm{mmol} / \mathrm{L}$, severe hypokalemia of $2.6 \mathrm{mmol} / \mathrm{L}$, bicarbonate level of $20 \mathrm{mmol} / \mathrm{L}$, anion gap of $29 \mathrm{mmol} / \mathrm{L}$, beta hydroxybutyrate of $1.75 \mathrm{mmol} / \mathrm{L}$, serum osmolality of 318 $\mathrm{mOsm} / \mathrm{kg}$; his acetaminophen level was negative at less than $10 \mathrm{ug} / \mathrm{mL}$, salicylate level was less than $1 \mathrm{mg} / \mathrm{dL}$ and hyperbilirubinemia level was at $3.2 \mathrm{mg} / \mathrm{dL}$. Initial venous blood gas showed a pH of 7.81 with a PCO2 of 11 and PO2 of 54. Arterial blood gas (ABG) was obtained to follow-up on the abnormal pH and on ABG pH was 7.63 with PCO2 of 26.6 , PO2 of 138 on room air, and bicarb was 28.2 with calculated oxygen saturations of $99 \%$. INR was at 1.1 and pro time was $12.9 \mathrm{~s}$, hemoglobin level $14.1 \mathrm{~g} / \mathrm{dL}$, macrocytosis with mean corpuscular volume $106 \mathrm{fL}$, mean corpuscular hemoglobin 37.9 PG, and thrombocytopenia with platelet count 100,000/uL. White blood cell count was noted to be normal. Urinalysis was positive for 2+ proteinuria, $2+$ glucosuria, and 3+ ketonuria.

Urine toxicology screen was positive for tetrahydrocannabinol. Two sets of blood cultures were done given lactic acidosis as a part of infectious work-up and was noted to be negative. COVID-19 rapid polymerase chain reaction (PCR) test was done and noted to be negative. Viral hepatitis panel was checked and was negative on admission. Given the abnormal labs and inconsistency with his history of isopropyl alcohol 


\section{Cureus}

ingestion especially given significantly elevated anion gap acidosis, consultation with a toxicologist was obtained. Upon review, the toxicologist was under the impression that the patient might have had possible mixed toxic alcohol ingestion and recommended the patient to be started on fomepizole drip with a loading dose of $50 \mathrm{mg} / \mathrm{kg}$ and to continue maintenance at $10 \mathrm{mg} / \mathrm{kg}$ every 12 hours for four doses. Also recommended to start the patient on leucovorin every six hours. The patient was also started on thiamine $500 \mathrm{mg}$ IV on day 1 and $100 \mathrm{mg}$ daily and $100 \mathrm{mg}$ of vitamin B6 daily on admission. He had also received $4 \mathrm{~g}$ of IV magnesium sulfate and $2 \mathrm{~g}$ of IV calcium gluconate. Given significant anion gap acidosis and lactic acidosis with severe electrolyte abnormalities, the patient was admitted to ICU for the first 24 hours. He was started on the Clinical Institute Withdrawal Assessment protocol given his known history of alcohol dependency. We did send out toxic alcohol levels to an outside lab and only acetone of $71 \mathrm{mg} / \mathrm{dL}$ was noted. Ethylene glycol, isopropyl alcohol, and methanol were not detected. Given that isopropyl alcohol, ethylene glycol and methanol were undetected, omeprazole and leucovorin were promptly discontinued. The patient also had a brief episode of nonsustained ventricular tachycardia likely secondary to severe hypokalemia which was promptly corrected with a total of $120 \mathrm{mEq}$ of oral potassium and $40 \mathrm{mEq}$ of IV potassium. The patient also had a prolonged OTC of $586 \mathrm{~ms}$ on admission and improved to $503 \mathrm{~ms}$ within 24 hours with electrolyte repletion. The patient had improved clinically and was discharged on day 4 of admission.

\section{Discussion}

Toxic alcohol ingestion can be fatal or produce irreversible tissue damage and hence timely recognition and treatment are very important. There are some key characteristics and clinical presentations that can help us achieve timely diagnosis aiding us in initiating appropriate treatment as soon as possible (Figure 1, Table 1).

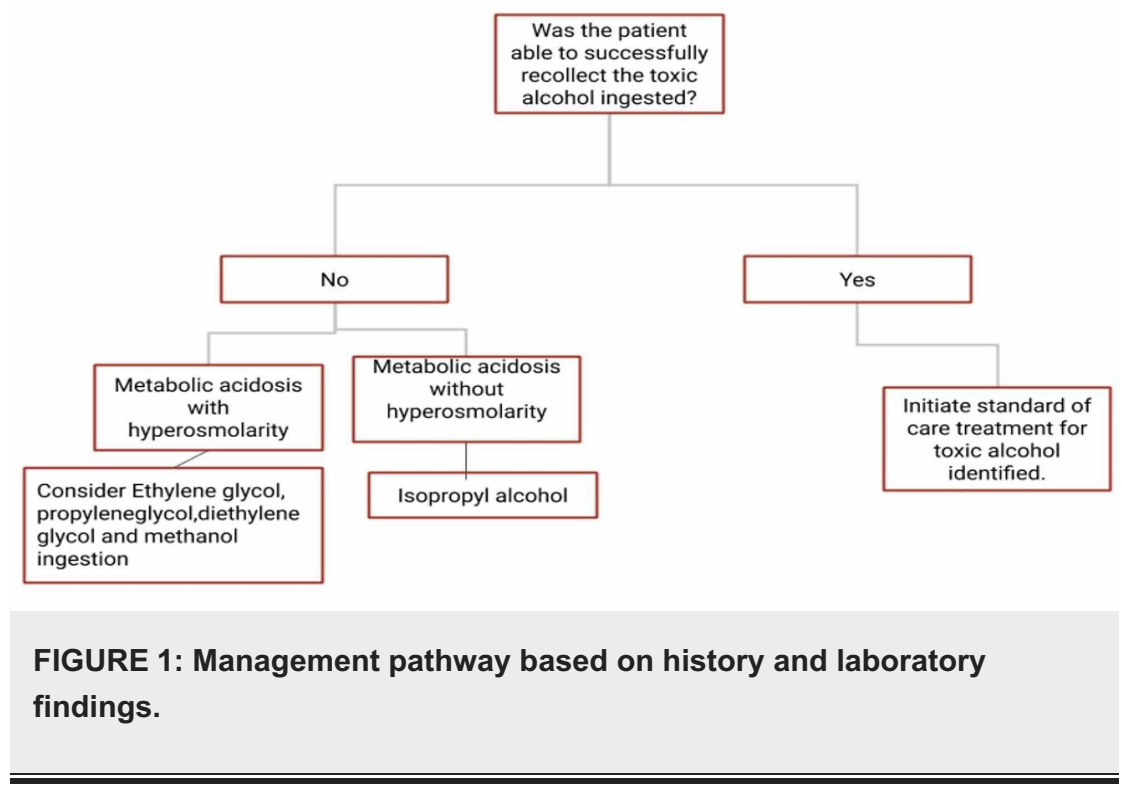




\begin{tabular}{|c|c|c|c|c|c|}
\hline $\begin{array}{l}\text { Type of } \\
\text { alcohol }\end{array}$ & $\begin{array}{l}\text { Toxicity } \\
\text { causing } \\
\text { substance(s) }\end{array}$ & $\begin{array}{l}\text { Common clinical } \\
\text { features }\end{array}$ & $\begin{array}{l}\text { Common } \\
\text { laboratory } \\
\text { abnormalities }\end{array}$ & Treatment & Comments \\
\hline Methanol & $\begin{array}{l}\text { Formic acid, } \\
\text { lactic acid, } \\
\text { ketones }\end{array}$ & $\begin{array}{l}\text { Retinal damage with } \\
\text { blindness, rarely } \\
\text { putaminal damage } \\
\text { with neurological } \\
\text { dysfunction }\end{array}$ & $\begin{array}{l}\text { Metabolic } \\
\text { acidosis with } \\
\text { hyperosmolarity }\end{array}$ & Fomepizole with or without hemodialysis & $\begin{array}{l}\text { Mortality rate } \\
\text { can be high if } \\
\text { not treated } \\
\text { quickly }\end{array}$ \\
\hline $\begin{array}{l}\text { Ethylene } \\
\text { glycol }\end{array}$ & $\begin{array}{l}\text { Glycolic acid, } \\
\text { calcium } \\
\text { oxalate }\end{array}$ & $\begin{array}{l}\text { Acute renal fallure, } \\
\text { myocardial and } \\
\text { cerebral damage }\end{array}$ & $\begin{array}{l}\text { Metabolic } \\
\text { acidosis with } \\
\text { hyperosmolarity }\end{array}$ & Fomepizole with or without hemodialysis & $\begin{array}{l}\text { Most common } \\
\text { toxic alcohol } \\
\text { ingestion } \\
\text { especially in } \\
\text { children }\end{array}$ \\
\hline $\begin{array}{l}\text { Isopropyl } \\
\text { alcohol }\end{array}$ & $\begin{array}{l}\text { Isopropyl } \\
\text { alcohol }\end{array}$ & Coma, hypotension & $\begin{array}{l}\text { Hyperosmolarity } \\
\text { without } \\
\text { significant } \\
\text { metabolic } \\
\text { acidosis }\end{array}$ & $\begin{array}{l}\text { Supportive treatment is usually sufficient, } \\
\text { initiate hemodialysis with serum level of } 200- \\
400 \mathrm{mg} / \mathrm{dL} \text { or in the presence of marked } \\
\text { hypotension, }\end{array}$ & $\begin{array}{l}\text { Positive } \\
\text { nitroprusside } \\
\text { reaction }\end{array}$ \\
\hline $\begin{array}{l}\text { Diethylene } \\
\text { glycol }\end{array}$ & $\begin{array}{l}\text { hydroxyethoxy } \\
\text { acetic acid }\end{array}$ & $\begin{array}{l}\text { Acute renal failure, } \\
\text { neurological } \\
\text { damage }\end{array}$ & $\begin{array}{l}\text { Metabolic } \\
\text { acidosis with } \\
\text { hyperosmolarity }\end{array}$ & Hemodialysis & $\begin{array}{l}\text { Associated } \\
\text { with high } \\
\text { mortality due } \\
\text { to late } \\
\text { recognition } \\
\text { and treatment }\end{array}$ \\
\hline $\begin{array}{l}\text { Propyiene } \\
\text { glycol }\end{array}$ & Lactic acid & $\begin{array}{l}\text { Minimal clinical } \\
\text { abnormalities }\end{array}$ & $\begin{array}{l}\text { Metabolic } \\
\text { acidosis with } \\
\text { hyperosmolarity }\end{array}$ & $\begin{array}{l}\text { Discontinue medication containing } \\
\text { patients with serum concentrations greater } \\
\text { than } 400 \mathrm{mg} / \mathrm{dL} \text { or severe lactic acidosis } \\
\text { might benefit from hemodialysis }\end{array}$ & $\begin{array}{l}\text { May be most } \\
\text { common } \\
\text { alcohol } \\
\text { intoxication in } \\
\text { ICU setting }\end{array}$ \\
\hline
\end{tabular}

TABLE 1: Brief overview of various toxic alcohols, their common clinical presentations, common laboratory abnormalities, and treatment.

Methanol intoxication can be seen in either accidental or intentional ingestion of adulterated alcohol or products with methanol and in rare cases can also be seen in inhalation of methanol. Ethylene glycol intoxication can be seen in accidental or intentional ingestion of antifreeze, alcohol adulterated with ethylene glycol, or products with ethylene glycol. Diethylene glycol intoxication is seen in ingestion of contaminated medication or products with diethylene glycol. Propylene glycol intoxication is usually seen in IV administration of medication with propylene glycol and rarely seen in ingestion of products with propylene glycol. Isopropyl alcohol intoxication can be seen in accidental or intentional ingestion of rubbing alcohol [1].

Diethylene glycol intoxication poses very high mortality possibly related to late recognition and treatment since it is most commonly associated with ingestion of contaminated medications or commercial products. Hyperosmolality can be less frequently seen then with other toxic alcohols. Ethylene glycol ingestion seems to be more frequently seen than methanol intoxication especially in children. The substances causing toxicity in methanol intoxication are formic acid, lactic acid, and ketones. Glycolic acid and calcium oxalate are the substances that cause toxicity in ethylene glycol intoxication. 2-

hydroxythoxyacetatic acid is the substance causing toxicity in diethylene glycol intoxication. Lactic acid is the substance causing toxicity in propylene glycol intoxication. Isopropanol is the substance causing toxicity in isopropanol intoxication [1].

The normal serum osmolality is around $285-290 \mathrm{mOsm} / \mathrm{L}$. Serum osmolality can be either calculated or measured by freezing point depression. Accumulation of the low molecular weight substances in the serum such as toxic alcohols will raise the measured serum osmolality producing an osmolal gap. Osmolal gap is the difference between measured and calculated serum osmolality $[1,3]$. The difference is usually within 10 mOsm/L. Serum osmolality can be calculated by using the following equation [1].

Serum osmolality $=2 \mathrm{XNa}+$ Blood urea nitrogen $(\mathrm{BUN}) / 2.8+$ Blood glucose $/ 18$.

Osmolal gap with high anion gap metabolic acidosis can be commonly seen in methanol, ethylene glycol, and diethylene glycol intoxications. Propylene glycol intoxication can cause osmolal gap with or without lactic acidosis. Isopropyl alcohol intoxication causes an osmolal gap without high anion gap metabolic acidosis. Anion gap varies depending on the time elapsed since ingestion of the toxic alcohol and the ongoing metabolism of the ingested toxic alcohol [2]. With time since ingestion increases, an increase in 
anion gap and a decrease in osmolal gap is observed [2]. Ethanol levels tend to increase the osmolal gap and it is vital to check its level as was done in our patient for accurate results [2]. Visual disturbances with optic papillitis can be seen in methanol intoxication. Osmolal gap with acute renal failure can be seen in patients with ethylene glycol and dietary glycol intoxication. Calcium oxalate crystals in urine, monohydrate or dihydrate crystals can be seen in ethylene glycol intoxication. Osmolal gap along with coma can be seen in diethylene glycol intoxication. Poor prognostic factors include blood $\mathrm{pH}$ with less than 7.1, severe lactic acidosis, severe hypotension, severe coma, acute renal failure requiring hemodialysis, and diagnosis greater than 10 hours after ingestion [1].

General principles and treatment of alcohol intoxication include gastric lavage or use of activated charcoal to remove alcohol from gastrointestinal tract but it needs to be initiated within 30-60 minutes after ingestion of alcohol. Administration of ethanol or fomepizole to delay or prevent generation of toxic metabolites needs to be initiated while sufficient alcohol remains to be metabolized and measurement of blood alcohol concentrations and/or serum osmolality can be helpful. The recommended dose of fomepizole for patients with methanol and ethylene glycol intoxication not requiring dialysis is a loading dose of 50 $\mathrm{mg} / \mathrm{kg}$ body weight with maintenance dose of $10 \mathrm{mg} / \mathrm{kg}$ body weight every 12 hours for four doses or 15 $\mathrm{mg} / \mathrm{kg}$ body weight every 12 hours. Dialysis is helpful in removing unmetabolized alcohol and possibly toxic metabolites and delivering base to patients to ameliorate metabolic acidosis. In patients requiring dialysis add $1-1.5 \mathrm{mg} / \mathrm{kg}$ body weight per hour to the standard dose of fomepizole. Hemodialysis can be initiated in all the toxic alcohol ingestion cases with poor prognostic factors and when serum concentration levels are readily available $[1-2]$.

\section{Conclusions}

Toxic alcohol ingestion is most often a challenging clinical situation for a physician. An accurate history may not always be available. Reliance on clinical features and laboratory findings is often needed by the clinician. Our case highlights the impedance a physician finds in such cases. Toxic alcohol ingestion requires time sensitive management measures. Assessment of the airway, contacting poison control, consideration of ethanol or fomepizole for blocking the toxic metabolites, correction of acidosis, replenishing of cofactors and correction of electrolyte abnormalities and assessing for the need of dialysis form the cornerstone of the management plan.

\section{Additional Information \\ Disclosures}

Human subjects: Consent was obtained or waived by all participants in this study. N/A issued approval N/A. Conflicts of interest: In compliance with the ICMJE uniform disclosure form, all authors declare the following: Payment/services info: All authors have declared that no financial support was received from any organization for the submitted work. Financial relationships: All authors have declared that they have no financial relationships at present or within the previous three years with any organizations that might have an interest in the submitted work. Other relationships: All authors have declared that there are no other relationships or activities that could appear to have influenced the submitted work.

\section{References}

1. Kraut JA, Kurtz I: Toxic alcohol ingestions: clinical features, diagnosis, and management . Clin J Am Soc Nephrol. 2008, 3:208-225. 10.2215/CJN.03220807

2. Gallagher N, Edwards FJ: The diagnosis and management of toxic alcohol poisoning in the emergency department: a review article. Adv J Emerg Med. 2019, 3:e28.

3. Krasowski MD, Wilcoxon RM, Miron J: A retrospective analysis of glycol and toxic alcohol ingestion: utility of anion and osmolal gaps. BMC Clin Pathol. 2012, 12:1. 10.1186/1472-6890-12-1

4. Alcohol Facts and Statistics. National Institute on Alcohol Abuse and Alcoholism . (2021). Accessed: January 2, 2021: https://www.niaaa.nih.gov/publications/brochures-and-fact-sheets/alcohol-facts-and-statistics.

5. Centers for Disease Control and Prevention (CDC). Alcohol and Public Health: Alcohol-Related Disease Impact (ARDI). Annual Average for United States 2011-2015 Alcohol-Attributable Deaths Due to Excessive Alcohol Use, All Ages.

https://www.cdc.gov/mmwr/volumes/69/wr/mm6930a1.htm\#: :text=During\%202011\%E2\%80\%932015\%20in\%20the,1)\%20(Table 